Rhode Island College

Digital Commons @ RIC

$1-1-2014$

\title{
Nurses Perceptions of Family Presence during Resuscitation in the Emergency Department
}

Jennifer L. Jennings

Rhode Island College

Follow this and additional works at: https://digitalcommons.ric.edu/etd

Part of the Critical Care Nursing Commons, and the Other Nursing Commons

\section{Recommended Citation}

Jennings, Jennifer L., "Nurses Perceptions of Family Presence during Resuscitation in the Emergency Department" (2014). Master's Theses, Dissertations, Graduate Research and Major Papers Overview. 239. https://digitalcommons.ric.edu/etd/239

This Major Paper is brought to you for free and open access by the Master's Theses, Dissertations, Graduate Research and Major Papers at Digital Commons @ RIC. It has been accepted for inclusion in Master's Theses, Dissertations, Graduate Research and Major Papers Overview by an authorized administrator of Digital Commons @ RIC. For more information, please contact digitalcommons@ric.edu. 
NURSES PERCEPTIONS OF FAMILY PRESENCE DURING

RESUSCITATION IN THE

\section{EMERGENCY DEPARTMENT}

By

Jennifer L. Jennings

A Major Paper Submitted in Partial Fulfillment

of the Requirements for the Degree of

Master of Science in Nursing

in

The School of Nursing

Rhode Island College

2014 


\begin{abstract}
Family presence during resuscitation has been a controversial and much debated topic for many years. In the past decade, the movement toward family presence has steadily grown. The Emergency Nurses Association (ENA) and the American Heart Association (AHA) have endorsed family presence and incorporated guidelines for its implementation. Although becoming more accepted in practice, there are still many hospitals without family presence policies, and some nurses and other health care providers continue to identify concerns about its' use. The purpose of this project was to survey nurses' perceptions of family presence during resuscitation in the Emergency Department. A researcher developed a survey which was left in the study site's Emergency Department break room for a period of two weeks. The target samples were Registered Nurses (RNs) employed in the ED. Thirteen out of 59 RNs completed the survey. More than half of the respondents believed in general that family should be present, that family presence encouraged increased professional behavior from the $\mathrm{RN}$, and families being present can facilitate closure. Recommendations and implications for advanced practice nursing and the need for future research are discussed.
\end{abstract}


Table of Contents

Background/Statement of the Problem......................................

Literature Review...................................................4

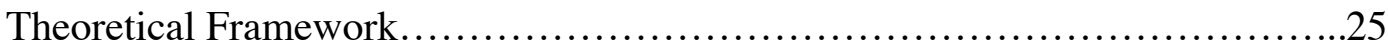

Methods..........................................................27

Results................................................................ 30

Summary and Conclusions............................................... 37

Recommendations and Implications for Advanced Nursing Practice............40

References..........................................................44

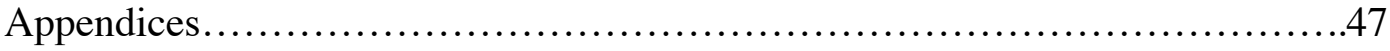




\section{Nurses' Perceptions of Family Presence during Resuscitation in the Emergency Department}

\section{Statement of the Problem}

Family presence at the bedside during resuscitation has been a controversial topic debated for many years. According to Maclean et al. (2003), family presence is defined as offering the choice to a patient's family member to stay with the patient in a location that affords visual and/or physical contact during an invasive procedure or cardiopulmonary resuscitation $(\mathrm{CPR})$.

Briguglio (2007) reported that the presence of family has been more accepted and supported in the pediatric population than with adults, since it is believed that family eases the patient's fear, provides comfort, and are a valuable source of information during an incident. The current debate focuses on this mindset as it relates to the adult population. Many fears and unsupported staff beliefs have thwarted family presence during resuscitation. According to Wagner (2004), these include: the family becoming disruptive and hindering care; the family's inability to handle the seriousness of the situation; the family's questioning of procedures used; increased vulnerability to litigation; and exposure to inappropriate comments made by staff in the heat of the moment.

Despite the traditional alienation of families during resuscitation, the Emergency Nurses Association (ENA), American Association of Critical-Care Nurses (AACN), and American Heart Association (AHA) promote the option of family presence and provide guidelines for its implementation (Knott \& Kee, 2005). The ENA first established family presence guidelines in 1995, with AHA and AACN following (MacLean et al., 2003). Supporters believe that family presence provides valuable benefits such as giving the family increased knowledge of what is happening, showing that all medical efforts were 
afforded to their family member, allowing for support and comfort of patient by the family, reducing family anxiety, and allowing for closure (MacLean et al.).

As advocates for change, nurses provide the impetus for allowing family presence. While doing so, they may find themselves in the midst of an ethical debate regarding benefits and risks related to allowing family members to enter the healthcare providers' private domain. Nurses perceptions of family presence are often welcoming yet guarded by a myriad of concerns such as increased vulnerability for litigation, stress and anxiety, and the fear of making a mistake (MacLean et al.). Nurses often feel that having a loved one at the bedside can provide closure when he/she is aware that every effort was made. Other benefits can include gaining a relationship and providing familial support (MacLean et al., 2003). Implementing family presence requires vigilant nurses who, during resuscitation, advocate for what is best for the patient, which may or may not include family presence at the bedside. Despite nurses being known as advocates for family presence, there has been limited research to assess nurses' opinions about this issue (Knott \& Kee, 2005).

Within the last decade, the movement to allow family presence has steadily grown. Family presence has been put into practice through the support of professional organizations such as ENA, which included family presence in its trauma nurse course curriculum (TNCC) and also in the emergency nursing pediatric course (ENPC) (MacLean et al., 2003). Despite this growth, as of 2007 only $5 \%$ of hospitals had a policy pertaining to family presence (Mian, Warchal, Whitney, Fitzmaurice and Tancredi, 2007). The purpose of this research study was to measure nurses' perceptions of family presence during resuscitation in the Emergency Department.

Next, the literature reviewed will be presented and discussed. 


\section{Review of Literature}

A literature review was conducted using the Cumulative Index to Nursing and Allied Health Literature (CINAHL) and Pub Med. Keywords used included; family presence during resuscitation; family presence during CPR; and nurses' beliefs during resuscitation. Articles and books used for this project were from the last 10 years, with the exception of one article from 1991, one article from 1992, and one book from 2000.

\section{Introduction: Family Presence}

Family presence, also referred to as family witnessed resuscitation (FWR), can be defined in multiple ways. Rattrie (2000) defined family presence as the practice of family presence while a loved one is being resuscitated. According to MacLean et al. (2003), family presence is the allowance of a patient's family to be at the bedside during resuscitation. It may also be defined as attendance of family in a patient care area in a location that allows visual or physical contact with the patient during resuscitation (Duran, Oman, Abel, Koziel, and Szymanski, 2007). Feagan and Fisher (2011) described FWR as a controversial topic in the acute care setting in regard to allowing family presence during resuscitation.

Foote Hospital, a 500-bed urban community hospital in Jackson, Michigan with an annual Emergency Department volume of 53,000, was the first to implement family presence during resuscitation in 1982. This was triggered by two occasions when family refused to leave during resuscitative efforts (Hanson \& Strawser, 1992). The program was developed in response to staff questions about the existing policy of excluding family members during resuscitation; the program was developed and implemented by the hospital chaplain, a small group of Emergency Department (ED) physicians, and ED nurses. The hospital chaplain served as a family liaison/advocate while the family was present in the room; in the event that the chaplain was not available, a nurse was assigned to that family. 
The hospital chaplain in 1985 mailed surveys to 47 family members of recently deceased patients to examine if they desired to be present during resuscitation. Thirteen out of the 18 surveyed (72\%) reported preference for being present during resuscitation. The survey revealed that $76 \%$ of family members $(n=33.8)$ felt that adjustment to the loved one's death was made easier by their presence in the room. Sixty-four percent ( $n=30)$ sensed that their presence was beneficial to the dying loved one. The family members reported that their presence during resuscitation attempts conveyed a sense of reality to their loss, allowing them to elude a prolonged period of denial that could interfere with the grieving process.

Staff members were also surveyed. Initially, the staff feared that the families' uncontrollable grief could disrupt the code team's duties, staff emotions could be aroused by family presence, and family observation could expose staff to litigation. After the nine-year initiative, the staffs' fears never materialized into major problems. It was reported that the staff maintained their clinical tasks as a priority and continued to function professionally. Often times the staff encouraged family members to be at the bedside and touch their loved one. Some nurses did feel stress during resuscitation, but many sanctioned the practice. Nurses noticed that family presence created an emotional bond with the RN and family, making it difficult for them to remain unattached during the code. With family presence, the patient was seen as part of a family unit and not as a single human being. This had both positive and negative effects on the staff. Positive effect was the patient was seen as a family unit, and the RN could care for the patient being resuscitated and their loved one. Negatively this was difficult to remain not emotionally attached to that family.

Post resuscitation, the chaplain conducted debriefings with involved staff members so that they could express their feelings. Recognizing the potential emotional toll on the staff, the possibility of implementing a critical incident stress team to assist 
with stressful situations was discussed. The information from these debriefings revealed that family members rarely disturbed resuscitation and often times were in awe of the activity in the room. Family members wanted to protect their loved one, so family members felt the need to remain vigilant. During crisis, families need reassurance, information, and support so they can cope effectively. The Foote Hospital study (1982) verified that many families lose autonomy and have no choice but to trust the controlling members of the healthcare team. With the loss of autonomy, they are denied the ability to provide protection and to cope with the situation effectively. Family presence during resuscitation can assist to meeting the identified needs of families.

\section{Family Presence Guidelines}

The Emergency Nurses Association (ENA) was the first major national organization to endorse family presence during resuscitation and invasive procedures. At the 1993 ENA annual conference, the organization acknowledged the practice of supporting family presence and created guidelines based on their belief that it was in the best interest of the patient and family (ENA). In 1995, the ENA published the original interdisciplinary guidelines and educational resources to support the enactment of family presence during resuscitation and invasive procedures within healthcare institutions. Since its original publication, the ENA published two more editions of the guidelines that address the importance of family presence, with the last edition in 2007 (ENA). The ENA has incorporated these guidelines into Emergency Nursing Pediatric Course (ENPC), Trauma Nursing Core Course (TNCC), and Pediatric Advanced Life Support (PALS) (ENA, 2007).

In addition to the ENA, multiple organizations such as the American Association of Critical-Care Nurses (AACN), Society of Critical-Care Medicine, the Canadian Association of Critical-Care Nurses, the National Association of Social Workers, the 
Emergency Medical Services for Children, and the National Association of Emergency Medical Technicians have all incorporated family presence in their field.

The American College of Emergency Physicians (ACEP) developed family presence guidelines for safe practice during resuscitation and urged that these guidelines be enforced during pediatric EDs (ENA, 2007). Family presence has also been adopted in several professional training curricula. The American Heart Association (AHA) assimilated family presence in their 2000 Guidelines for Cardiopulmonary Resuscitation and Emergency Cardiopulmonary Resuscitation and Emergency Cardiovascular Care and it continues to be included in its' 2005 and 2010 updates. The recommendations set forth by AHA suggested that healthcare providers should promote the opportunity for family presence during resuscitation (AHA, 2010). Since its introduction in 2000, family presence has steadily become an integral part of the AHA guidelines. In each update, 2005 and 2010, family presence has become an increasingly recommended technique used during crisis. As stated in the 2010 AHA guidelines, "In the absence of data documenting harm and in light of data suggesting it may be helpful, offering select family members the opportunity to be present during resuscitation is reasonable and desirable (assuming the patient, if an adult, has not raised a prior objection)" (AHA, p.670).

\section{Family Members' Perspectives of Family Presence}

Wagner (2004) completed a survey in a 700 bed urban community hospital with participants 18 years of age or older. The purpose of the survey was to depict experiences and thoughts of family members after witnessing CPR in the Intensive Care Unit. Family members whose loved ones survived were asked to participate in the survey within 24 hours of the resuscitation. The families were asked five open-ended questions to describe the events that occurred during resuscitation including: 'Where did the resuscitation take place?'; 'Was family allowed in the room?'; 'Was support available?' 
and 'Was a healthcare provider delivering updates?'. A major struggle that emerged was the question of whether the family should be present in the room or excuse themselves to address other needs. Participants stated that they were anxious about the decision to stay with their loved ones or go elsewhere to take care of other needs. The more information provided by the healthcare team, the easier the decision was for the family. Families felt helpless during this time and placed a remarkable amount of trust in the healthcare team to care for their loved one. Wagner noticed a common theme of families mentally struggling to stay at the bedside or leave the room of their loved one. Three phases, labeled as pre-jive, here- and- now, and breaking the rules, were identified.

During the pre-jive phase, family members acknowledged changes in their loved ones' condition that signaled something was wrong, and then alerted the healthcare team. When the family was satisfied with the care that their loved one received, the family would exit the room. Here-and-now was the phase of crisis for both the patient and family. The family found themselves negotiating to be present during resuscitation while the staff was asking them to step out of the room. The family felt powerless and helpless with the healthcare team now in the control of the situation. Families wondered what was going on with their loved one and hoped to receive information. The last phase was breaking the rules phase. This occurred after successful resuscitation when the patient was stabilized and the family was vigilant at the bedside waiting for answers as to what the next course of action would be. Family could break the rules formally or informally to be with their loved one. Formal rule breaking included not following the hours of permitted visitation of that unit, and informal rule breaking included activities that were under the discretion of the nurse.

Mazer, Cox and Capon (2006) conducted a survey to determine public opinions of witnessed CPR. The survey was completed via phone interviews of 408 people over the age of 18 . The sample of participants was randomly chosen from a list of people residing 
within Memorial Medical Center's service area in Pennsylvania. The telephone survey tool was developed to retrieve information based on Centers for Disease Control and Preventions' Behavioral Risk Factor Surveillance System survey. Respondents were also questioned about end-of-life planning. Questions pertinent to this project pertained to witnessing CPR, having CPR performed on them, seeing CPR performed on loved ones, and who should make the decisions to allow family presence. Over one third of respondents $(37.3 \% ; \mathrm{n}=152)$ stated a desire to be present while their loved one was receiving CPR. Forty-three percent of the participants $(n=175)$ thought the physician should have the most authority for making the end of life decisions closely, followed by patients $(40 \%$; $n=163)$. Only $17 \%$ of participants $(n=69)$ believed that family and friends should have the primary right to make the decision to allow family presence.

\section{Effects of Family Presence on Family and Staff}

The objective of a study conducted by Duran, Oman, Abel, Koziel, and Szymanski (2007) at the University of Colorado Hospital was to describe and compare the beliefs and attitudes of clinicians, families, and patients toward family presence. Surveys were completed by 202 clinicians in the ED, Intensive Care Unit (ICU), and Neonatal Intensive Care Unit (NICU), as well as by 72 family members and 62 patients. Inclusion criteria for the patients and family members included their having witnessed resuscitation. If they stated yes and agreed to participate, the survey questions were asked verbally. Clinician surveys were mailed via interdepartmental mail. The survey consisted of 47 open-ended questions for the healthcare providers and family members, while the patient survey consisted of 42 open-ended questions.

Of the 202 health care providers who returned the survey, there were 98 nurses, 98 physicians, and 6 respiratory therapists. Overall, healthcare providers' attitudes were positive about family presence, with respiratory therapist ranking the highest. Consistent with other studies, about two thirds of healthcare providers had been previously involved 
with family presence during resuscitation $(66 \% ; n=131 / 198)$. Healthcare providers who supported family presence during resuscitation had significantly higher Mean Family Presence Attitude (M-FPAS; range = 1-4) (M-FPAS 2.7, SD 0.45) than those who did not support the practice (M-FPAS 2.38, SD 0.48); $(P<.001)$. A trend toward differing attitudes between nurses and attending physicians and non-attending physicians (interns, residents, and fellows) was demonstrated. Similar to other studies, nurses were more favorable toward family presence (M-FPAS 2.65, SD 0.45) than physicians (M-FPAS 2.3, SD 0.51); $(\mathrm{P}<.001)$. The authors noted that nurses tended to be the advocates for family presence, whereas physicians were often hesitant and focused attention on patient and not the family. Among physicians themselves, interns, residents, and fellows had more positive attitudes (M-FPAS 2.4, SD 0.44) than attendings (M-FPAS 2.38, SD 0.48); $(P<.001)$. Sixty-nine percent of nurses favored policy development as opposed to only $46 \%$ of physicians.

The authors found frequent comments from healthcare providers that included worries about family members getting in the way and disturbing the code, and attention focused on the family member instead of the patient. Healthcare providers were concerned about the emotional toll on family. Specifically, they identified concerns about the families' memory of the last moments of their loved ones' lives becoming traumatized by witnessing the resuscitation. They also identified concerns about the inability to control emotions and to potentially interfere with care. Finally, the healthcare providers expressed a potential barrier of performance anxiety of staff, which could produce stress. Providers did not want to feel like they were on display, especially if the outcome was bad. Even though healthcare providers favor family presence, they are fearful regarding performance anxiety. Family presence in some facilities is a novice idea and many of the healthcare providers will not be comfortable until experience is gained. 
Mian et al. (2007) advocated for a family presence program within the Emergency Department (ED) at Massachusetts General Hospital. The authors researched the attitudes of nurses as well as physicians before and after the launch of the program. An anonymous three-part survey was administered to all ED nurses, attending physicians, and residents on two separate occasions: prior to the start of the program and one year after induction of the program. The survey measured the healthcare professionals' willingness to adopt family presence, personal and professional experience of family presence, and demographics. Education was conducted with the staff over a three-month period. The sessions included descriptions of current research findings, a brief video of an actual family describing their own personal experience, and findings from the survey. Members of the investigating team during resuscitations would ask the participating team members if they would be comfortable offering family presence. If the team agreed, the researching group functioned as a support/advocate for the family members. After completion of the resuscitation, the researchers provided feedback from the family members to the resuscitating team.

Eighty-six nurses and 35 physicians completed the initial survey. Concerns of both physicians and nurses were legal and malpractice issues, interference with teaching of residents, and anxiety. In the initial survey, $71 \%(n=86)$ of nurses supported family presence, in comparison to $51 \%(n=35)$ of physicians. Eighty-nine nurses and 14 physicians completed the follow up survey. On the follow up survey, nurses' support of family presence was higher than the initial survey. Thirty-nine percent $(n=89)$ of nurses expressed a more positive attitude regarding family presence after an education program. Thirty-six percent $(n=89)$ of the nurses that already had a positive attitude prior to the program implementation showed an increase in positivity after program implementation. The physician's follow-up survey results cannot be determined since only one out of 14 physicians attended and completed the survey. 
According to the authors, once staff felt comfortable with the family being present at the bedside, nurses began to initiate family presence more routinely, and this was eventually adopted into nursing practice. Staff nurses became the champions for family presence and provided discussions to those physicians who were reluctant to incorporate the family. As evidenced by the surveys, nurses strongly supported the rights of patients and their families to family presence. Nurses disclosed fewer practice concerns and had a change in attitude after witnessing the connection between the patient and family and establishing a relationship with the family.

In both stages of the survey, the participating physicians had lower support for family presence. Despite this, the post-survey revealed increased physician support from the pre-survey however these findings are greatly limited by the low response rate of physicians to the follow up survey. Even though some reported increased concerns on post-survey, Mian et al. believed that the increased concerns could be related to the lack of experience especially from residents and new attendings. Overall, it appeared that with education and experience, nurses and physicians were willing to accept family presence during resuscitation but at varying percentages.

Feagan and Fisher (2011) conducted a two-phase study with physicians and registered nurses regarding their opinions and beliefs of family-witnessed resuscitation (FWR). The study took place at a 388-bed trauma center and a 123-bed community hospital in eastern Washington State. The objective of the study was to evaluate education on FWR and support of FWR as an extension of family-centered care. Phase I sought local trends in health care provider attitudes toward the option of family presence during resuscitation. The result of the survey was used to provide information to develop an education program aimed at common concerns among acute care physicians and nurses. 
A convenience sample was enlisted from all health care providers in the emergency departments and in patient units of both facilities. During phase I, surveys were disseminated to 55 physicians and 465 nurses in both facilities. The survey included basic demographics, educational level, and frequency of experience with resuscitation during the last 12 months, prior FWR education, and the number of FWRs. Results demonstrated that physicians with less than five years of experience scored lower (mean 2.25; SD, 0.68 range $=1-4)$ than more experienced physicians (mean 3.14; SD, 1.21 range $=1-4)(P<.05)$ in support of FWR. Those physicians who had prior education on FWR were more favorable toward FWR (mean 2.86; SD, 1.46; $P<0.5$ ). In regard to nurses, there was no relationship between a positive attitude toward FWR and frequency of resuscitation or the number of experiences with FWR. The study did find that nurses with prior FWR education were more likely to support it ( $\mathrm{n}=24$; mean 3.17; SD, 0.868).

The purpose of phase II, conducted at a nonacademic facility, was to determine the effect of an educational program that incorporated evidence-based information on clinician acceptance of FWR. During phase II, pre/post-education surveys were developed and disseminated, along with a 40-minute education program highlighting the restraining and driving forces of change for FWR. Of the 83 educational program attendees, 44-pre-education surveys were returned. The post education surveys were returned by 25 nurses, for a 30\% return rate; no physicians returned the survey. Overall, attitudes were more positive for FWR $(P<.05)$. Despite the low survey return, the results determined that providers with prior education and experience with family presence were more supportive to it than those without.

Kosowan and Jensen (2011) conducted a study of beliefs and barriers surrounding family presence by health care professionals working in Canadian Cardiac Units in Edmonton. They adapted a survey that had been developed by ENA which examined the participants' prior experience with family presence, perceived barriers and benefits of 
family presence, and perceptions towards policies and procedures regarding family presence. The participants included registered nurses, licensed practical nurses, nurse practitioners, clinical nurse educators, physicians, fellow/residents, medical students, pharmacists, occupational health, physiotherapists, respiratory therapists, and hospital chaplains. One hundred sixty nine healthcare professionals responded to the survey; more than half $(69.5 \% ; n=110)$ reported that they provided psycho-social-spiritual support to family members. Forty-four percent $(n=75)$ assumed that family should not have the option to be present at the bedside. Less than half of the respondents $(40.9 \%$; $\mathrm{n}=69$ ) strongly agreed or agreed to give family members the option to be present during CPR. Of the participants, $43.8 \%$ strongly agreed that family presence during CPR is a patient/family right. Conversely, the respondents $(45 \% ; n=76)$ alleged that family presence would interfere with patient care and 61.5\%; $(\mathrm{n}=103)$ agreed that family presence would be stressful for the team members. Only a small percent $(15.3 \%$; $n=26)$ of respondents believed that their risk for litigation would be higher if excluding family members. An astounding $72.2 \%(\mathrm{n}=122)$ of health care professionals preferred family presence for themselves. The reasoning for this was to advocate/aid in decision making, understand the severity, decrease family anxiety and fear, support and comfort, and to visualize that all interventions were done. Health care professionals' greatest reservation regarding family presence was the fear of lack of support for the family.

Jabre et al. (2013) performed a multicenter, randomized controlled trial, the purpose of which was to determine whether offering a family member the choice of witnessing CPR decreased the amount of post-traumatic stress disorder (PTSD), anxiety, and/or depression related symptoms. The authors examined 15 French pre-hospital emergency medical service units that were ambulance-based stations staffed by a driver, a nurse, and a senior emergency physician. The study included 570 family members of adult patients in cardiac arrest occurring at home. Two hundred and sixty-six families 
were systematically given the option of being present (intervention group) and three hundred and four families (control group) were not routinely asked during resuscitation. The study also considered the healthcare team stress level with family presence and surveyed the occurrence of medical legal conflicts.

Ninety days after the incident, a trained psychologist asked enrolled relatives to answer a structured questionnaire by telephone. The questions were derived from the Impact of Event Scale (IES), and the Hospital Anxiety and Depression Scale (HADS). Four hundred and seventy-eight family members (83\%) completed the IES survey. The control groups' $(n=304)$ had response rates that were significantly higher $(P=0.004)$ than the intervention group $(n=266)$ secondary to emotional distress of not being present during the resuscitation (adjusted odds ratio, 1.7; 95\%). Frequency of PTSD symptoms was significantly higher $(P=0.004)$ in the control group as compared to the intervention group. Anxiety was significantly higher in the families who did not witness the resuscitation as compared to the witnessing family $(P<0.001)$. Symptoms of depression did not differ significantly between the two groups $(P=0.13)$, but demonstrated lower among family members who were present (adjusted odds ratio, 1.6 95\% CI, 1.1 to 2.5; $P=0.02$ ) than those who were absent (adjusted odds ratio, $1.7 ; 95 \%$ CI 1.2 to 2.51 ; $P=0.004)$.

The median stress levels of the healthcare team members $(n=570)$ were measured on a visual analogue scale; no significant differences in stress levels were identified. As for medical-legal conflicts, no claims were made from any of the participating family members. The study demonstrated that the witnessing families had a significantly lower incidence of PTSD related symptoms and anxiety. In addition, the responses revealed that neither the effectiveness of resuscitation nor the duration of CPR was affected by the witnessing family members being present. A key desire among respondents was to be present while CPR was being performed on a loved one. A major 
finding from the study was that individuals who desire CPR are generally more likely to have positive feelings towards witnessed resuscitation than those not desiring CPR

Downar and Kritek (2013), both physicians and experts in their fields, gave their opinions for family presence while reviewing the Jabre et al. article (2013). Downar described his opposition to family presence, identifying a concern that it could interfere or alter the performance with resuscitation efforts and may increase the risk of death of the patient. Downar was also fearful that the family might suffer from physical or psychological effects and the healthcare team could incur legal repercussions. Downar stressed the psychological trauma to the family and questioned if this harm is mitigated by presence of a resuscitation team member (family liaison). Downar stated that more information is needed about the mechanisms of harm and benefit that relate when family members are present during resuscitation.

Kritek's view was opposite of that of Downar. Kritek felt that having a dedicated staff liaison as part of the resuscitation team can ensure that family do not impede resuscitation efforts. He supported the implementation of guidelines for family presence. Kritek believes that guidelines, when combined with staff training including scenario simulation, ensure that the measures are conducted properly. By way of this practice, Kritek believed that the staff develops the necessary comfort and performance level needed when faced with inclusion of family members at the bedside. Kritek suggested that incorporating family consistently with resuscitations would make it easier. Providers would gain an additional sense of comfort with each experience and it would become second nature to them. Kritek concluded that the oath of being a physician is to help patients and their families institute goals of care, process life threatening events, and try to establish the best death possible by allowing relatives to be with their loved ones (Downar and Kritek, 2013).

\section{Nurses' Perception of Family Presence}


MacLean et al. (2003) randomly mailed a 30-item survey to 1500 members of both the AACN and the ENA. The purpose of the study was to identify critical care and emergency nurses current practices policies, and preferences for family presence. Only $5 \%$ of the respondents $(n=49)$ worked on units that had current written policies to include families during CPR and $1 \%(n=12 / 953)$ had policies not to include family. Forty-five percent $(n=422 / 943)$ of the nurses stated that their facility didn't have a policy in place to allow or prohibit families from being at the bedside, but allowing loved ones into the room was part of their current practice. More than one third $(37 \%$; $n=365 / 984)$ of the critical care/emergency nurses preferred a written policy allowing the option of family during CPR, and 35\% $(n=347 / 984)$ preferred a written policy for family presence during invasive procedure. Greater than one third $(39 \%$; $=386 / 984)$ of the nurses preferred the option of having family presence but didn't feel the need to have a policy. Forty-one percent $(n=407 / 984)$ preferred giving family the option of being present during invasive procedures, but without a policy.

Common themes reported by nurses regarding family presence included: provides emotional support for patients and families; provides a positive experience for families, patients and staff; provides guidance and increases family understanding of the patient's situation; helps families make decisions about resuscitation; helps families know that everything was done to save their loved one; and facilitates closure and healing. Staff were concerned with the negative implications of family presence such as: privacy and limited benefits; family behaviors, lack of education and understanding, emotional reactions, family-staff relationships; staff stress and discomfort, extra work and burden, and inadequate staffing; limited space, chaos and confusion, and lack of privacy in the room; family issues; and legal complaints. Nurses believed that it would be beneficial to designate a staff person to be the families advocate and support while at the bedside (MacLean et al., 2003) 
Knott and Kee (2005) performed a study to explore the nurses' beliefs and experiences concerning family presence at the bedside during resuscitation efforts. The study utilized a 16-question qualitative interview and assessed for common themes. The sample included 10 registered nurses with a minimum of four years of clinical experience who worked in an acute care setting. The nurses were selected using variation sampling. Four themes emerged: the conditions during which family presence is an option; using family presence to force family decision making; staff feelings of being watched; and the impact of family presence on a family.

The first theme was identified as 'conditions during which family presence was not a practical option'. Some participants noted that allowing a loved one at the bedside during resuscitation was dependent on the conditions or situations that contributed to the need for resuscitation. Many nurses were concerned with the potential of family interference at the bedside. Family members could sometimes be out of control, not know how to deal with their emotions, and possibly get in the way. Other nurses felt that the family presence was contingent on the situation surrounding the need for resuscitation. The second theme was 'an influential tool to help families decide to carry on or cease resuscitative efforts'. The attendance of family in the room during resuscitation allowed the visualization of what was involved during resuscitation and assisted the family to decide if all heroic measures should be performed at length.

The third theme was awareness of being watched by family and the staffs' behavior. Some of the respondents felt an increase in anxiety and a hovering feeling. This theme was especially felt when certain interventions failed to result in a positive change in the patients' condition. Many of the nurses stated that they perceived themselves as the focus of attention, with everyone watching their performance. While some nurses felt empathy for the loved ones watching their family members, some expressed that they felt as if their attention was divided between 'two' instead of 
concentrating on 'one'. Additionally, several nurses expressed that staff behavior was often different with family presence. Usually during resuscitation, the room was reported as being loud. With family presence, it was noted to often be quiet, for the fear of the nurse/medical team saying something inappropriate and the family misconstruing what was said as being disrespectful. Respondents noted that to get through difficult situations, the medical staff can be unpolished and verbal and not realize what is being said in the heat of the moment. Staff also stated that in some instances the providers might have performed an outstanding job and the family would be eternally grateful.

The final theme was the 'impact of family presence on the family'. Many of the respondents felt that family presence could provide insight about the care that their loved one had received and closure for the family. Numerous participants stated the importance of family members being able to be present and visualize the immediate attention provided by many staff members (Knott \& Kee, 2005).

A study performed by Twibell et al. (2008) at Ball Memorial Hospital in Indiana focused on understanding nurses' perceptions of benefits, risks, and self-confidence with family witnessed resuscitation. A total of 375 nurses (Licensed Practical Nurses and Registered Nurses) working on all units of the hospital and of all experience levels participated in the study. The participants completed the Family Presence Risk-Benefit Scale (FPR-BS) and the Family Presence Self-Confidence Scale (FPS-CS). Also included were questions related to the participants' demographics, including if they belonged to a professional organization and/or held a certification in their specialty, organization risks-benefits, and participants' self-confidence, and was based on a five point Likert scale.

Two-thirds of the respondents $(n=254)$ had never invited a family member to be present during resuscitation, greater than $20 \%(n=83)$ had invited family to be present less than five times, and $7.5 \%(\mathrm{n}=28)$ had invited family five or more times. Scores on 
the FPR-BS demonstrated a significant difference between nurses who did and those who did not belong to a professional nursing organization $(t=5.3, P<.001)$ or were not certified in a specialty $(t=3.9, P<.001)$. In regard to scores on the FPS-CS, nurses who were certified and belonged to professional organizations alleged more benefits and fewer risks than did noncertified and nonmember nurses and scored higher $(t=5.1, P<$. 001). Comparing perceptions of family presence did not vary when looking at the nurses' educational background. In contrast, LPNs professed fewer benefits, more risks $(F=$ $14.3, P<.001)$, and less self-confidence with family presence than RN's $(F=2.76, P=$. 04). Years of nursing experience for both LPNs and RNs were not related to nurses' perceptions of risks, benefits, or self-confidence. Emergency Department nurses perceived fewer risks, more benefits, and greater self-confidence when compared to noncritical units. The study reported that professional organizations support family inclusion during resuscitation with the presence of guidelines. However, not all nurses agreed with the risks and benefits involved. More than half of the nurses' expressed family presence during resuscitation was a right for both patients and their families. Results suggest that the perceptions of nurses who have invited family presence differ from those lacking experience with it (Twibell et al., 2008).

Throughout the reviewed literature, it has become apparent that family presence during resuscitation has become a gold standard in healthcare. Despite some concerns and hesitation by those in practice, the research data shows only limited, if any, negative impact for allowing this process of involving family. Family can witness that every life saving measure is performed and without having any questions as to what was going on during the resuscitation. Moreover, there has been a consistent pattern of positive impact on family emotion and closure. Unfortunately, the majority of the studies conducted included small samples and was predominantly descriptive, with no randomized controlled trials. Thus, findings may not be generalizable to healthcare providers overall. 
Next, the theoretical framework guiding this program development will be discussed. 


\section{Theoretical Framework}

\section{The Relationship-Based Care: A Model for Transforming Practice}

The theoretical framework selected to guide this research study is RelationshipBased Care: A Model for Transforming Practice by Koloroutis et al. (2004). The major purpose for the development of the Relationship-Based Care (RBC) was to transform nursing practice. There are three fundamentals that encompass the RBC model: nurses' relationship with patients and their families; nurses' relationship with self; and nurses' relationship with colleagues (Koloroutis et al.).

The healthcare provider-patient relationship main objective is a consistent focus on the patient and the family. The healthcare provider identifies that each patient/family's life story will convey how they experience an illness. The healthcare provider delivers respect and understanding of what is most important to the patient and family while actively engaging them in all facets of care. The RBC framework identifies that caring and healing principles are those in which there is a palpable and visible regard for the dignity of human beings, relationships between healthcare team members, the people they serve, and a commitment to healing (Koloroutis et al., 2004). RBC model fits this project as it looks not only at the patient who is being cared for, but incorporating the family in the patients care. Healthcare providers now realize that a patient is not always a single unit but seen as a group.

The second vital piece is the nurse's relationship with oneself. This relationship is fostered by self-knowing and self-care. Self-knowing is a requirement to building healthy relationships and honing one's ability to empathize. If a person is uncertain about their own emotional maturity, it can hinder the ability for caregiving and teamwork. Self-care is the ability for one to effectively manage one's own stress, express personal needs/values, and balance the demands of the job with one's physical and emotional health and well-being (Koloroutis et al., 2004). The RBC model and this 
project are intrigued to appreciate nurse's opinions of family presence and the impact on values and the possible stress it can have.

The third vital relationship is among the colleagues of the healthcare team and their ability to function cohesively to provide compassionate care, respect each other, and maintain interpersonal relationships. Relationship-based care can successfully provide positive outcomes in clinical safety, quality, and family/staff satisfaction (Koloroutis et al., 2004). The third vital relationship and this project collectively look at professionalism and if the healthcare team can function cohesively and fluidly while having family presence.

The major thrust of RBC is to focus a on the provision of consistent, competent care to the patient and family while understanding the nurses' self as well as their interaction with team members. This framework is consistent with the purpose of this study: to measure nurses' perceptions of family presence during resuscitation within the Emergency Department. 


\section{Methodology}

\section{Purpose/Research Question}

The purpose of this research study was to measure nurses' perceptions of family presence during resuscitation in the Emergency Department. The research question was: What are nurses' perceptions of family presence during resuscitation?

\section{Design}

This research study used a mixed method of quantitative survey and open-ended question.

\section{Sample}

The study used a purposive non-probability sample. Inclusion criteria included RNs employed in the ED, with no restrictions on shift worked, employment status, educational level, years of experience status, age, or ethnicity. The ED Director, two shift managers, and ED Educator were included as potential participants. Exclusion criteria included float pool RNs. A goal of one third of the potential 59 ED RNs was desired $(n=19)$.

\section{Site}

The study was conducted at a local 255-bed community hospital in Warwick, R.I. The ED has 42 beds, with an annual patient census of 60,000. The hospital did not have a policy related to family presence during resuscitation at the time of the study.

\section{Procedure}

Permission to conduct the study was obtained from Director of the Emergency Department, and two shift Managers of the Emergency Department. Institutional Review Board (IRB) approval was obtained from Rhode Island College (RIC) and the community hospital's IRB. The community hospital IRB was approved via expedited review and approved by the Chief Nursing Officer, Chief Medical Officer, and a Physician from Internal Medicine. 
The researcher emailed the ED Director and two ED Managers to remind them of the study and the survey prior to the survey disbursement. Three days before the survey was placed in break room, an email was sent out to all RNs within the ED explaining the purpose of study, stressing that participation in the study was voluntary, and also identifying the incentive for participation. A manila envelope that contained the IRB approved informational letter (Appendix A) and the survey (Appendix B) were stapled together then placed on the break room table in the ED. A copy of the IRB approved informational letter and surveys were placed on the front of the envelope. Staffs were instructed to carefully read the informational letter and complete the survey voluntarily if they were interested. As an incentive for completing the survey, each participant was given a raffle entry for a chance to win a $\$ 50.00$ gift card to the hospital gift shop. Each survey had a raffle ticket attached to it; when the participant completed the survey, the participant kept one side of the ticket and the remaining part of the raffle ticket was placed in a box with the completed surveys until the drawing. Participants were instructed to drop the completed, anonymous survey in a sealed box that was placed on the shelving unit behind the break room table.

After the two-week survey period, a raffle ticket was drawn at random by the ED administrative assistant and the winning number was displayed in the ED break room. The winner was asked to pick up their winnings at the ED administrative assistant office, allowing the winner to remain anonymous to the researcher.

\section{Measurement}

An 11 question survey was created by this researcher, based on the review of the literature, particularly the ENA 2007 survey (ENA, 2007) and clinical experience. The survey was designed to elicit RNs perceptions of family presence during resuscitation (Appendix B). Question 1-10 included a forced-choice response format with a 5-point Likert scale, and the last question was open ended. The survey was pilot tested for 
understandability and usability with three RNs who worked in the Education Department. The three pilot RN's unanimously stated the survey was easy to understand and complete.

\section{Data Analysis}

Data gathered were entered into a Microsoft Excel ${ }^{\circledR}$ spreadsheet for the purposes of organizing the survey data. Basic descriptive statistics were used to analyze responses, including means, and percentages. The one open ended question was analyzed by looking for common themes. All data will be stored in a locked file cabinet for three years at the community hospital. 


\section{Results}

Of the 59 possible participants, 13 ED nurses completed the survey (22.3\%). All were RNs, with educational levels spanning from Diploma to Bachelor's degrees: one (7.6\%) had a Diploma; six (46.1\%) had an Associates; and six (46.1\%) had a Bachelor's degree. Emergency Department nursing experience ranged from 1.5 years to 37 years, with an average of 13 years of experience. Eight participants (61.5\%) had 1-10 years' experience, three (23.1\%) had 11-20 years 'experience, and two (15.4\%) had 30 plus years of experience. Ages ranged from 24 to 63 years, with the highest percentage $(30.7 \% ; n=3)$ in the $31-40$ year age range.

Nurses completed a two part survey: the first 10 questions were based on a 5 point Likert scale, and the last question was open ended. Strongly agree was given a number one, whereas strongly disagree was a five. Table 1 illustrates the 10 Likert response questions, the participants' responses to the 10 survey questions, and the average response for each question. 
Table 1

Family Presence Survey

\begin{tabular}{|c|c|c|c|c|c|c|}
\hline Question & $\begin{array}{c}\# \\
\text { Strongly } \\
\text { Agree }\end{array}$ & $\begin{array}{c}\# \\
\text { Agree }\end{array}$ & $\begin{array}{c}\# \\
\text { Neutral }\end{array}$ & $\begin{array}{c}\# \\
\text { Disagree }\end{array}$ & $\begin{array}{c}\# \\
\text { Strongly } \\
\text { Disagree }\end{array}$ & Mean \\
\hline $\begin{array}{l}\text { 1. Believe in general family } \\
\text { should be present during } \\
\text { resuscitation }\end{array}$ & 5 & 4 & 1 & 1 & 2 & 2.3 \\
\hline $\begin{array}{l}\text { 2. Family presence } \\
\text { encourages increased } \\
\text { professional behavior from } \\
\text { RN }\end{array}$ & 4 & 3 & 3 & 0 & 2 & 2.4 \\
\hline $\begin{array}{l}\text { 3. Family presence can } \\
\text { increase anxiety/stress of } \\
\text { the resuscitation team }\end{array}$ & 2 & 4 & 2 & 3 & 2 & 2.9 \\
\hline $\begin{array}{l}\text { 4. Family may misinterpret } \\
\text { healthcare teams activities } \\
\text { as harmful }\end{array}$ & 2 & 5 & 2 & 2 & 2 & 2.8 \\
\hline $\begin{array}{l}\text { 5. Family presence during } \\
\text { resuscitation can facilitate } \\
\text { family closure }\end{array}$ & 4 & 5 & 2 & 1 & 1 & 2.2 \\
\hline $\begin{array}{l}\text { 6. Families should be } \\
\text { welcomed into } \\
\text { resuscitation room }\end{array}$ & 4 & 4 & 2 & 3 & 0 & 2.3 \\
\hline $\begin{array}{l}\text { 7. Family members present } \\
\text { during resuscitation will } \\
\text { understand patient's } \\
\text { condition }\end{array}$ & 4 & 3 & 5 & 1 & 0 & 2.2 \\
\hline $\begin{array}{l}\text { 8. Family presence during } \\
\text { resuscitation increases risk } \\
\text { for litigation }\end{array}$ & 1 & 2 & 1 & 7 & 2 & 3 \\
\hline $\begin{array}{l}\text { 9. Family members could } \\
\text { potentially disrupt } \\
\text { resuscitation }\end{array}$ & 2 & 5 & 3 & 0 & 3 & 2.8 \\
\hline $\begin{array}{l}\text { 10. Verbal communication to } \\
\text { team members may be } \\
\text { limited with family } \\
\text { presence }\end{array}$ & 2 & 2 & 4 & 3 & 0 & 2.3 \\
\hline
\end{tabular}

Table 1 data were collapsed into agree and disagree responses to more clearly illustrate the responses in terms of agreement and disagreement (Table 2). 
Table 2

Family Presence Survey Responses Collapsed by Agreement and Disagreement

\begin{tabular}{|c|c|c|c|}
\hline Question & $\begin{array}{c}\# \\
\text { Overall } \\
\text { Agree }\end{array}$ & $\begin{array}{c}\# \\
\text { Neutral }\end{array}$ & $\begin{array}{c}\# \\
\text { Overall } \\
\text { Disagree }\end{array}$ \\
\hline $\begin{array}{l}\text { 1. Believe in general family } \\
\text { should be present during } \\
\text { resuscitation }\end{array}$ & 9 & 1 & 3 \\
\hline $\begin{array}{l}\text { 2. Family presence encourages } \\
\text { increased professional behavior } \\
\text { from RN }\end{array}$ & 7 & 3 & 2 \\
\hline $\begin{array}{l}\text { 3. Family presence can increase } \\
\text { anxiety/stress of the } \\
\text { resuscitation team }\end{array}$ & 6 & 2 & 5 \\
\hline $\begin{array}{l}\text { 4. Family may misinterpret } \\
\text { healthcare teams activities as } \\
\text { harmful }\end{array}$ & 7 & 2 & 4 \\
\hline $\begin{array}{l}\text { 5. Family presence during } \\
\text { resuscitation can facilitate } \\
\text { family closure }\end{array}$ & 9 & 2 & 2 \\
\hline $\begin{array}{l}\text { 6. Families should be welcomed } \\
\text { into resuscitation room }\end{array}$ & 8 & 2 & 3 \\
\hline $\begin{array}{l}\text { 7. Family members present during } \\
\text { resuscitation will understand } \\
\text { patient's condition }\end{array}$ & 7 & 5 & 1 \\
\hline $\begin{array}{l}\text { 8. Family presence during } \\
\text { resuscitation increases risk for } \\
\text { litigation }\end{array}$ & 3 & 2 & 8 \\
\hline $\begin{array}{l}\text { 9. Family members could } \\
\text { potentially disrupt resuscitation }\end{array}$ & 7 & 3 & 3 \\
\hline $\begin{array}{l}\text { 10. Verbal communication to team } \\
\text { members may be limited with } \\
\text { family presence }\end{array}$ & 4 & 4 & 3 \\
\hline
\end{tabular}

As can be seen in Table 2, more than half of respondents believed: in general that family should be present $(n=9)$; that family presence encourages increased professional behavior from $\mathrm{RN}(\mathrm{n}=7)$; that family may misinterpret healthcare team's activities as harmful $(n=7)$; that family presence during resuscitation can facilitate family closure (n =9); that families should be welcomed into the resuscitation room $(n=8)$; that family members present during resuscitation will understand patient's condition $(n=7)$; and that family members could potentially disrupt resuscitation $(n=7)$. In addition, eight out of thirteen nurses believed that family presence can decrease the risk for litigation. 
Several of the survey questions reflect 'negative' questions, including items 3, 4, 8,9 , and 10 . For ease of interpretation, the 'positive' survey questions and participants' responses are illustrated in Table 3, with the 'negative' survey questions and responses displayed in Table 4.

Table 3

Positive Survey Questions

\begin{tabular}{|l|c|c|c|}
\hline \multicolumn{1}{|c|}{ Question \# } & $\begin{array}{c}\# \\
\text { Overall Agree }\end{array}$ & $\begin{array}{c}\# \\
\text { Neutral }\end{array}$ & $\begin{array}{c}\# \\
\text { Overall } \\
\text { Disagree }\end{array}$ \\
\hline $\begin{array}{l}\text { 1.Believe that in general family members } \\
\text { should be present during resuscitation if } \\
\text { they wish to be }\end{array}$ & 9 & 1 & 3 \\
\hline $\begin{array}{l}\text { 2.Believe that family presence encourages } \\
\text { increased professional behavior from RN's }\end{array}$ & 7 & 3 & 2 \\
\hline $\begin{array}{l}\text { 5.Believe that family presence during } \\
\text { resuscitation can facilitate closure for the } \\
\text { family }\end{array}$ & 9 & 2 & 2 \\
\hline $\begin{array}{l}\text { 6.Believe that families in general should be } \\
\text { welcomed into the resuscitation room }\end{array}$ & 8 & 2 & 3 \\
\hline $\begin{array}{l}\text { 7.Believe that family members who are } \\
\text { present during resuscitation will better } \\
\text { understand the patient's condition }\end{array}$ & 7 & 5 & 1 \\
\hline
\end{tabular}


Table 4

Negative Survey Question

\begin{tabular}{|l|c|c|c|}
\hline \multicolumn{1}{|c|}{ Question \# } & $\begin{array}{c}\# \\
\text { Overall Agree }\end{array}$ & $\begin{array}{c}\# \\
\text { Neutral }\end{array}$ & $\begin{array}{c}\# \\
\text { Overall } \\
\text { Disagree }\end{array}$ \\
\hline $\begin{array}{l}\text { 3.Believe that family presence in the } \\
\text { resuscitation room causes increased anxiety } \\
\text { and/or stress on the resuscitation team }\end{array}$ & 6 & 2 & 5 \\
\hline $\begin{array}{l}\text { 4.Believe that family may misinterpret } \\
\text { activities of the healthcare team that occur } \\
\text { during resuscitation as harmful }\end{array}$ & 7 & 2 & 4 \\
\hline $\begin{array}{l}\text { 8.Believe that family presence during } \\
\text { resuscitation potentially increases risk for } \\
\text { litigation }\end{array}$ & 3 & 2 & 3 \\
\hline $\begin{array}{l}\text { 9.Believe that family members could } \\
\text { potentially disrupt resuscitation effort }\end{array}$ & 7 & 4 & 3 \\
\hline $\begin{array}{l}\text { 10.Believe that verbal communication to } \\
\text { other team members may be limited by } \\
\text { family presence }\end{array}$ & 4 & 4 & 8 \\
\hline
\end{tabular}

As reflected in Table 3, overall nurses supported the concept of family presence and agreed that it helped to facilitate closure for the family $(n=9)$. Eight nurses believed that family should be welcomed in the resuscitation room, but two disagreed. While the majority of participants believe that family members who are present during resuscitation will better understand the patient's condition $(n=7)$, it is noteworthy that five nurses were neutral and one disagreed.

Table 4 displayed the negative survey questions and the overall responses. While Table 3 overall reflected support for family presence by the majority of nurses, responses in Table 4 clearly illustrated that nurses also have concerns about family presence. The majority of nurses indicated that family may misinterpret the healthcare team activities as harmful $(n=7)$, and could potentially disrupt the resuscitation $(n=7)$. Most $(n=8)$ however, disagreed that family present could contribute to the risk for liability.

The last question of the survey asked nurses: "Please explain your experience with family witnessed resuscitation. If you do not have any experience to please write 
none". Table 5 illustrates answers from eight out of the 13 participants who had experience with family presence.

\section{Table 5}

Nurses' Experience with Family Presence

1. Family presence is case dependent benefits vs. advantages

2. Situation and people/family understand what is happening where others don't fully understand. One experience the wife and daughter requested to be present and everything that was being done was explained. Another experience family was screaming and interrupting the resuscitation.

3. Many times family witness's resuscitation there is a greater understanding of resuscitation efforts and ease with transitions through stages of grief.

4. Family members sat quietly in room and were not a hindrance. Also as a recommendation to only allow two family members in the resuscitation room this will allow a lesser distraction for the team.

5. A husband watched as his wife was passing, and he was glad he could witness all the efforts. Throughout the resuscitation a sense of professionalism was noted.

6. Family was aware and understood what was going on with their loved one. Family is more comfortable with outcome whether it be good or bad.

7. Family members present during resuscitation have a greater understanding of the situation and find peace with the outcome.

8. Family member requested to not leave his mother during resuscitation. Unfortunately, the resuscitation was not successful. The code team was very quiet during resuscitation but everything was done correctly.

A common theme was that nurses believed $(n=6)$ that loved ones had a better

understanding of what was going on with in the resuscitation room and allowed for an easier transition through the grief process. Other themes that emerged were allowing only two family members in the resuscitation room to assist with overcrowding $(n=1)$, and educating the ED staff could mitigate in staff intimidation of family presence $(n=1)$. In general, the nurses had positive experiences with family presence.

Next, summary and conclusions will be discussed. 


\section{Summary and Conclusions}

Family presence at the bedside during resuscitation has been a controversial topic debated for many years. Briguglio (2007) reported the presence of family has been more accepted and supported in the pediatric population. Family presence has been_accepted in pediatrics that family being present eases the patient's fear, provides comfort, and serves as a valuable source of information during an incident. In the last decade the movement to allow family presence has steadily grown. There is evidence in the literature that family presence during adult resuscitation has become more accepted as a standard practice, and the results of the survey conducted in the project reflect that shift.

Family presence has been increasingly translated into practice through the support of professional organizations such as ENA, which included family presence in its trauma nurse core course and emergency nursing pediatric curriculums (MacLean et al., 2003). Allowing family presence can provide family with the needed understanding of what is going on during the resuscitation, and in some instances, and help to provide closure.

The purpose of this project was to survey RNs in a local community hospital ED regarding their perceptions of family presence during resuscitation. At the time of the study, the hospital study site did not have a family presence policy in place, and allowing family members in the resuscitation room was at the discretion of the nurse. An 11 question survey to measure nurses' perceptions of family presence was developed by the student investigator, based on the review of literature, particularly that of the ENA 2007 (ENA, 2007), as well as clinical experience. During a two-week period, data were collected through ED nurses' voluntary completion of this survey.

Of the 59 possible participants, 13 ED nurses completed the survey (22.3\%). More than half of respondents believed: in general that family should be present $(n=9)$; 
that family presence encourages increased professional behavior from $\mathrm{RN}(\mathrm{n}=7)$; family may misinterpret healthcare teams activities as harmful $(n=7)$; family presence during resuscitation can facilitate family closure $(n=9)$; families should be welcomed into the resuscitation room $(n=8)$; family members present during resuscitation will understand patient's conditions $(\mathrm{n}=7)$; and family members could potentially disrupt resuscitation $(n=7)$. Of the 13 nurses who participated, eight had experience with family presence during resuscitation. Each of these nurses had positive opinions and believed that allowing the family to be present provided them with the opportunity to understand facts and circumstances surrounding their loved one's condition as well as a means of closure.

Several limitations of this project are acknowledged. The researcher hoped that at least one third of the 59 eligible RNs would participate. Thirteen nurses participated, with an overall response rate of $22.3 \%$. Two potential contributors to the lower than desired response rate were identified. The first was the two-week response deadline requested by this investigator; the concentrated time frame may have limited the opportunity for nurses to participate. Second, the ED was operating at a high patient census at the time of the survey. This may have prevented the nurses from taking their customary breaks, and thus to voluntarily complete the survey, which were made available only in the ED nurses' break room. Another limitation was that the survey used in the project was developed by the investigator, and thus reliability and validity have not been established. While no attempt was made to gather extensive demographic data, it should be acknowledged that the respondents were primarily Caucasian females; lack of ethnic and gender diversity may have limited responses.

In conclusion, although limited in scope, the results of the survey indicated that ED nurses in general have a positive perception of family presence. The findings will be presented to the ED Director and other key individuals within the institution. 
Anticipated goals will be establishment of a family presence policy in the ED and potentially throughout the institution. Initially, ED nurses with prior family presence experience may be essential in promoting the implementation of the practice and may be an essential resource in the development of written policies and hospital training. The APRN can also potentially play a pivotal role in development and implantation of a family presence policy.

Next, recommendations and implications for advanced practice will be presented. 


\section{Recommendations and Implications for Advanced Nursing Practice}

The Nurse Practitioner must be continually vigilant about the need to maintain and improve quality of care for patients and families. Advanced practice registered nurses (APRNs) are respected as change agents and leaders in regard to disseminating the most current best practice guidelines and informing others about these changes. It is imperative that the APRN maintain organizational involvement to understand the essential elements required to make a practice change within a clinical area and the overall system.

Understanding that outcome measurements are the backbone of hospital reimbursement rates, APRNs can assist with ensuring that policies and education promote the most efficient use of staff, time, and resources throughout the treatment process for patients and families. Recommended by ENA and AHA, one of the new standards designed to improve patient and family outcomes is family presence. Healthcare organizations need to be prepared to identify and provide the most cost effective, yet safe, way to implement this concept. Program design and implementation, including the development of written policies and standardized training for staff is essential to promote implementation of family presence. Acute Care Nurse Practitioners, who are actively involved in resuscitations, can be pivotal in transitioning this best practice to the bedside. Literature supports that overall, nurses view family presence more positively than physicians (Duran et al., 2007), and NPs have the potential to influence physician as well as nursing attitudes and behaviors in this regard.

Support for family presence has been provided by ENA and AHA, and each hospital should review its policies related to family presence, or in many cases, their lack of such policies. Healthcare organizations hopefully continue to shift toward a more patient driven focus, there is an opportunity to embrace family friendly policies overall, in addition to that of family presence. Primary advocates for patients and families, 
nurses, and APRNs in particular, can play a central role in advocating for family friendly healthcare environments.

Family dynamics are often challenged during times of stress, and careful consideration needs to be given as to how families who are not coping successfully should be managed in terms of family presence. Support systems need to be in place both for families who are responding 'appropriately' and those who are not. An ethical concern that needs to be considered is the nature of the relationship between family members and the patient; this can be particularly challenging during crisis. In addition, hospitals need to consider whether limiting the number of family members allowed into the room is warranted. Social workers and ED family assistants can be used to assist RNs in managing family members during crisis, thus allowing nurses to perform their job functions with minimal interruption. Interdisciplinary practice should be utilized as a means to mitigate potential problems and improve the family presence experience for staff, families, and patients.

While the ENA and AHA have taken stands in support of family presence, further policy work at the national level is needed to foster this movement. Additionally, family presence research needs to be conducted to support and potentially enhance the backing from these organizations. Research to determine the prevalence of family presence in health care organizations throughout the nation is needed. Much of the research conducted to date has been descriptive and has focused on views of hospital staff in regard to family presence. Research needs to be developed with the family perspective in mind; if being present during resuscitation isn't consistently helping families cope, then all of the other views and opinions are moot. Further study of family presence in adult populations, using similar methods and other than descriptive designs will enhance the ability to generalize results. Developing a solid body of research evidence will 
potentially assist organizations that have been hesitant to implement family presence policies to address identified concerns and move forward.

Training of health profession students as well as multidisciplinary staff can be obtained through high fidelity simulation; a multidisciplinary team can conduct family presence training within the hospital, and the APRN can assume a leadership role in this regard. Participants, whose support for family presence can be expected to vary, will have the opportunity to learn from each other. Team leaders have the potential to craft standardized policies for the hospital industry while improving education and related training for hospital staff. This training can include themes pertaining to the understanding of family dynamics, the importance of family, and dealing with families in crisis to name a few topics.

In summary, APRN's can play a pivotal role in initiating family presence as a standard of practice. The need for organizational support, collaborative resources, and education for staff are critical elements. Although limited in scope, the results of this survey indicated that ED nurses are becoming more accepting of family presence. Emergency Department nurses with prior family presence experience may be essential in promoting the implementation of the practice and may be an essential resource in the development of written policies and hospital training. 


\section{References}

American Heart Association (2000). Guidelines 2000 for cardiopulmonary resuscitation and emergency cardiovascular care. Circulation, 102(8).

American Heart Association (2010). Guidelines 2010 for cardiopulmonary resuscitation and emergency cardiovascular care. Circulation, 110 (9).

Briguglio, A. (2007). Should the family. RN, 70, 42-48.

Downar, J. \& Kritek, P. A. (2013). Family presence during cardiac resuscitation. The New England Journal of Medicine, 368, 1060-1062.

Duran, C. R., Oman, K. S., Abel, J. J., Koziel, V. M., \& Szymanski, D. (2007). Attitudes toward and beliefs about family presence: A survey of healthcare providers, patients' families, and patients. American Journal of Critical Care, 16, 270-282.

Emergency Nurses Association (2007). Emergency Nurses Association: Presenting the option for family presence (3rd ed.). Des Plaines, IL:

Feagan, L. M. \& Fisher, N. J. (2011). The Impact of education on provider attitudes toward family-witnessed resuscitation. Journal of Emergency Nursing, 37, 231239.

Guzzetta, C. E., Clark, A. P., \& Halm, M. A. (Eds.). (2007). Review of the Literature on Family Presence. Presenting the Option for Family Presence (Third ed., pp. 722). Des Plaines, IL:

Hanson, C.,\& Strawser, D. (1992). Family presence during cardiopulmonary resuscitation: Foote Hospital emergency department's nine-year perspective. Journal of Emergency Nursing, 18, 104-106.

Jabre, P., Belpomme, V., Azoulay, E., Jacob, L., Bertrand, L., Lapostolle, F. \& Broche, C. (2013). Family presence during cardiopulmonary resuscitation. The New England Journal of Medicine, 1008-1018. 
Knott, A. \& Kee, C. C. (2005). Nurses' beliefs about family presence during resuscitation. Applied Nursing Research, 18, 192-198.

Koloroutis, M., Dingman, S., Felgen, J., Kinnaird, L., Manthey, M., Person, C., \& Wright, D. (2004). Relationship-based care: A model for transforming practice. Minneapolis, MN.

Kosowan, S. \& Jensen, L. (2011). Family presence during cardiopulmonary resuscitation: Cardiac health care professional's perspectives. Canadian Journal of Cardiovascular Nursing, 21, 23-29.

MacLean, S. L., Guzzetta, C. E., White, C., Fontaine, D., Eichhorn, D. J., Meyers, T., \& Desy, P. (2003). Family presence during cardiopulmonary resuscitation and invasive procedures: Practices of critical care and emergency nurses. Journal of Emergency Nursing, 29, 208-221.

Mazer, M. A., Cox, L. A., \& Capon, A. (2006). The public's attitude and perception concerning witnessed cardiopulmonary resuscitation. Critical Care Medicine, 34 , 2925-2928.

Mian, P., Warchal, S., Whitney, S., Fitzmaurice, J., \& Tancredi, D. (2007). Impact of a multifaceted intervention on nurses' and physicians' attitudes and behaviors toward family presence during resuscitation. Critical Care Nurse, 27, 52-61.

Rattrie, E. (2000). Witnessed resuscitation. Good practice or not? Nursing Standard, 14(24), 32-35.

Twibell, R. S., Siela, D., Riwitis, C., Wheatley, J., Riegle, T., Bousman, D., \& Harrigan, S. (2008). Nurses' perceptions of their self-confidence and the benefits and risks of family presence during resuscitation. Retrieved from http://ajcc.aacnjournals.org

Wagner, J. M. (2004). Lived experience of critically ill patient's family members during cardiopulmonary resuscitation. American Journal of Critical Care, 13, 416-420. 
Appendix A

Informational Letter

January 27, 2014

Dear Fellow Colleague,

You are being asked to participate in a research study about nurses' perceptions of family presence during resuscitation as part of the requirements to complete a Master of Science in Nursing at Rhode Island College. You are identified as a possible participant because all Registered Nurses employed in the ED at Kent County Memorial Hospital are invited to voluntarily participate. Please read this letter and ask any questions you might have.

The purpose of this research is to explore nurses' perceptions of family presence during resuscitation within the Emergency Department. If you choose to participate, you will be asked to complete an 11 item survey that will take about five minutes of your time.

Surveys will be located in a manila envelope in the break room from January 27, 2014 thru February 10, 2014. Once the survey is completed, please place it in the sealed box on the bookcase in the break room.

There are no identified risks of participating in this survey. Your responses to the surveys are anonymous and will remain confidential and only the faculty advisor and myself will review them.

There are no direct benefits to you for participating in this study. As a thank you for your participation, you will have a chance to win a $\$ 50.00$ gift card to the hospital gift shop. Please remove and retain one end of the raffle ticket located on the top right corner of the 
survey. When the survey is completed on February 10, 2014 all raffle tickets will be placed into a drawing and on February 11, 2014, a ticket will be pulled at random. The winning number will be displayed on the break room message board. In order to claim your prize, the winning nurse will bring the ticket to Liz Ferland (the ED administration Assistant) who will award the gift card. The winner will remain anonymous to me. Thank you.

Your participation is completely voluntary and is not required by your job. If you have any questions, please contact me via pager at 582-9727 or call me at extension 31954.

By completing this survey you have agreed to participate in the research project.

Respectfully,

Jennifer Jennings, BSN, RN, MSN student

Off-Shift Clinical Educator

Appendix B

Nurses' Perceptions of Family Presence During Resuscitation Survey

Age:

Highest level of Education

Years of Emergency Department experience

Please answer each of the following 10 questions to indicate how strongly you agree or disagree regarding each statement. Please circle one of the five responses per question.

\begin{tabular}{|c|c|c|c|c|c|}
\hline \multirow[b]{2}{*}{ Survey Item } & \multicolumn{5}{|c|}{ Responses } \\
\hline & $\begin{array}{l}\text { Strongly } \\
\text { Agree }\end{array}$ & Agree & Neutral & $\begin{array}{c}\text { Dis- } \\
\text { agree }\end{array}$ & $\begin{array}{l}\text { Strong- } \\
\text { ly Dis- } \\
\text { agree }\end{array}$ \\
\hline $\begin{array}{l}\text { 1.I believe that in general } \\
\text { family members should } \\
\text { be present during } \\
\text { resuscitation if they } \\
\text { wish to be. }\end{array}$ & $\mathrm{SA}$ & $\mathrm{CA}$ & $\mathrm{CN}$ & $C D$ & $\mathrm{CD}$ \\
\hline $\begin{array}{l}\text { 2.I believe that family } \\
\text { presence encourages } \\
\text { increased professional } \\
\text { behavior from RN's. }\end{array}$ & $\mathrm{SA}$ & $\mathrm{CA}$ & $\mathrm{CN}$ & $C D$ & $\mathrm{SD}$ \\
\hline $\begin{array}{l}\text { 3.I believe that family } \\
\text { presence in the } \\
\text { resuscitation room } \\
\text { causes increased anxiety } \\
\text { and/or stress of the } \\
\text { resuscitation team }\end{array}$ & $\mathrm{CSA}$ & $\mathrm{CA}$ & $\mathrm{CN}$ & $C D$ & $\mathrm{SD}$ \\
\hline $\begin{array}{l}\text { 4.I believe that family may } \\
\text { misinterpret activities of }\end{array}$ & $\mathrm{CSA}$ & $\mathrm{CA}$ & $\mathrm{CN}$ & $C D$ & $\mathrm{CSD}$ \\
\hline
\end{tabular}




\begin{tabular}{|c|c|c|c|c|c|}
\hline $\begin{array}{l}\text { the healthcare team that } \\
\text { occur during } \\
\text { resuscitation as harmful. }\end{array}$ & & & & & \\
\hline $\begin{array}{l}\text { 5.I believe that family } \\
\text { presence during } \\
\text { resuscitation can } \\
\text { facilitate closure for the } \\
\text { family. }\end{array}$ & $\mathrm{CSA}$ & $\mathrm{CA}$ & $\mathrm{CN}$ & $C D$ & $C \mathrm{SD}$ \\
\hline $\begin{array}{l}\text { 6.I believe that families in } \\
\text { general should be } \\
\text { welcomed in the } \\
\text { resuscitation room. }\end{array}$ & $\mathrm{CSA}$ & $C A$ & $\mathrm{CN}$ & CD & $C \mathrm{SD}$ \\
\hline $\begin{array}{l}\text { 7.I believe that family } \\
\text { members who are } \\
\text { present during } \\
\text { resuscitation will better } \\
\text { understand the patient's, } \\
\text { condition. }\end{array}$ & $\mathrm{CSA}$ & $C A$ & $\mathrm{CN}$ & $C D$ & $C \mathrm{SD}$ \\
\hline $\begin{array}{l}\text { 8.I believe that family } \\
\text { presence during } \\
\text { resuscitation potentially } \\
\text { increases risk for } \\
\text { litigation. }\end{array}$ & $\mathrm{CSA}$ & $C A$ & $\mathrm{CN}$ & $C D$ & $C \mathrm{SD}$ \\
\hline $\begin{array}{l}\text { 9.I believe that family } \\
\text { members could } \\
\text { potentially disrupt } \\
\text { resuscitation effort. }\end{array}$ & $\mathrm{CSA}$ & $C A$ & $\mathrm{CN}$ & $C D$ & $C \mathrm{SD}$ \\
\hline $\begin{array}{l}\text { 10.I believe that verbal } \\
\text { communication to other } \\
\text { team members may be } \\
\text { limited by family } \\
\text { presence. }\end{array}$ & $\mathrm{CSA}$ & $C A$ & $\mathrm{CN}$ & CD & $C \mathrm{SD}$ \\
\hline
\end{tabular}

In the space provided below, please explain your experience with family witnessed resuscitation. If you do not have any, please write NONE.

Thank you for your participation. 
